\title{
Forest Sustainability in North Lebanon: A Challenging Complexity in a Changing Environment
}

\author{
Rita El-Hajj, ${ }^{1,2}$ Dalia Al-Jawhary, ${ }^{3}$ Tala Moukaddem, ${ }^{3}$ and Carla Khater ${ }^{1,2}$ \\ ${ }^{1}$ National Council for Scientific Research, Center for Remote Sensing, P.O. Box 11-8281, Riad el Solh, Beirut, Lebanon \\ ${ }^{2}$ Mada Association, Atallah Building, 20 Al Arid Street, Ain el Remmaneh, Beirut, Lebanon \\ ${ }^{3}$ Society for the Protection of Nature in Lebanon, Hamra, Abdel Aziz Street, P.O. Box 11-5665, Beirut, Lebanon
}

Correspondence should be addressed to Carla Khater; ckhater@cnrs.edu.lb

Received 3 March 2014; Revised 30 May 2014; Accepted 30 May 2014; Published 16 July 2014

Academic Editor: Piermaria Corona

Copyright (C) 2014 Rita El-Hajj et al. This is an open access article distributed under the Creative Commons Attribution License, which permits unrestricted use, distribution, and reproduction in any medium, provided the original work is properly cited.

\begin{abstract}
Forests sustainability is a challenging task in a complex socioeconomic context. North Lebanon is a critical zone harboring forests of key ecological value and is one of the most deprived regions in Lebanon with high poverty rates, where forests are heavily impacted by unsustainable anthropogenic practices. In the global frame of climate change scenarios, this paper tests a multistakeholder, multidisciplinary approach for forest management, combining a joint participatory methodology with stakeholders along with field ecological surveys in the upper Akkar watershed (north Lebanon). A set of participatory tools including stakeholder's analysis, problem tree, objective tree, and scenario building are tailored to reach this goal. Results exhibit that forest management is not only related to forests per se but also very much linked to the surrounding socioeconomic situation. Involving not only strict silviculture interventions but also a definite consideration of community needs and local economy, the adoption of a multitool, multidisciplinary, multistakeholder approach combines all possible aspects of a challenging context and unfolds complementary processes which all feed back into one target. Yet, it is a time-consuming process, which can easily drown financial and temporal resources and which can sometimes raise unrealistic expectations that are difficult to meet.
\end{abstract}

\section{Introduction}

Forests are essential for human survival and well-being. They harbor two-thirds of all terrestrial animal and plant species and provide food, oxygen, shelter, recreation, and spiritual sustenance, as well as over five thousand commercially traded products, ranging from pharmaceuticals to timber and clothing [1]. Mediterranean forests in particular harbor a distinctive mix of stands offering various types of vital resources and services to the societies and economies bordering the Mediterranean basin [2]. However, the unsustainable and abusive use of forest resources as well as the changes in land use patterns in northern and southern Mediterranean has led to the depletion of their assets and will predictably contribute to a pronounced fragmentation in the 20 coming years [3]. The plodding effects of climate change will mainly exacerbate the consequences [4], especially that scientific evidence is further demonstrating that the climate is indeed changing
$[4,5]$, even if the range of changes and the global distribution of the impacts are less apparent [6].

In this evolving natural and socioeconomic context, sustainable, integrated, and participatory forest management is considered the ultimate solution [7-9]. The General Assembly of the United Nations adopted in December 2007 the most widely intergovernmental agreed definition of sustainable forest management [10]: "a dynamic and evolving concept aiming to maintain and enhance the economic, social, and environmental values of all types of forests, for the benefit of present and future generations. It is characterized by seven elements, including extent of forest resources; forest biological diversity; forest health and vitality; productive functions of forest resources; protective functions of forest resources; socioeconomic functions of forests; and legal, policy, and institutional framework." In simpler terms, forest sustainability implies the achievement of a balance between societies' increasing demands for forest products and benefits 
and the preservation of forest health and diversity [11]. This balance is critical to the survival of the forests and the prosperity of forest-dependent communities. Recognizing this complex yet delicate interaction, a wide array of sometimes conflicting factors ranging between commercial and noncommercial values, environmental considerations and ecological priorities, community needs, and global climate impacts must be acknowledged to achieve a sustainable forest management [12]. Emerging insights from adaptive ecosystem management and new institutional economics suggest that building resilience into both human and ecological systems is the optimal way to deal with future surprises or sudden risks such as climate change impacts [13].

Located at the crossroads of three continents, on the eastern shores of the Mediterranean Sea, Lebanon is recognized as the cradle of many civilizations supporting intensive anthropogenic activities. These activities have imprinted its biological and physical environment including species richness and landscape as well as its forests' structure and composition [14]. Variations in human land-use patterns and site-specific histories of resources management, which often resulted in overexploitation and resource depletion, have had a profound impact on forests throughout the country [15]. Hence, most of Lebanon's forests are heavily utilized by man and are thus frequently severely impacted and are increasingly vulnerable to human triggered actions such as urban sprawl, road network development, quarrying, overgrazing, overharvesting, uncontrolled logging, abusive hunting, forest fires, invasive species, pollution, and soil erosion [16].

North Lebanon is a critical and unique zone sheltering high rates of genetic, specific, and ecosystemic diversity, delineated by changes in types and structures as well as differences in living standards caused by discrepancies in livelihoods [17]. It is one of the most deprived regions in Lebanon with high rates of illiteracy and marginality [18]. Forests in north Lebanon cover approximately $21 \%$ of the northern governorate and encompass most of the forest species present in Lebanon, namely, Quercus calliprinos (Palestine oak), Quercus infectoria (Aleppo oak), Quercus cerris (Turkey oak), Juniperus excelsa (Greek juniper), Juniperus drupacea (Syrian juniper), Cedrus libani (Cedar of Lebanon), Abies cilicica (Cilicica fir), Pinus pinea (Stone pine), Pinus brutia (Calabrian pine), and Cupressus sempervirens (Mediterranean cypress). However, alike other forests, those of north Lebanon are profoundly impacted by engrained unsustainable anthropogenic practices which radically challenge the survival of the species and the resilience of the stands [19], where $C$. libani, A. cilicica, Q. cerris, and J. excelsa have been identified as having the lowest natural adaptive capacity to current and future climate trends $[4,20]$. A decade of research on climate change vulnerability also proved that it is indeed the poorest and the most vulnerable societies which most suffer from the impacts of changing environmental conditions [2123]. Building resilience, which involves increasing the ability of a system (social and ecological) to withstand shocks and surprises and to revitalize itself if damaged, offers the prospect of a sustainable response.
In this multifaceted context, how to sustain forest resources in a continuously evolving complex socioecological system?

Recognizing the fact that livelihoods and forest sustainability are mutually dependent, intertwined elements and that sustainability of ecosystems is closely related to sustainability of livelihoods [24], we tested in this study a multidisciplinary multistakeholder approach in the upper Akkar watershed (north Lebanon), a region harboring relic broadleaved stands and high altitude mixed conifers forests of key ecological value. Thus, not only have we considered the forests as sole entities to orient their management but also we widened the scope to a whole watershed, where communities and resources interact and where every socioeconomic aspect can influence natural resources management, especially forest resources.

\section{Methodology}

In an evolving socioecological context, a multistakeholder approach is a key to a successful management process. Therefore, a joint participatory planning with local and national stakeholders directly and indirectly involved in the upper Akkar's forest resources management was applied. This method is inspired from the International Union for Conservation of Nature (IUCN) approach for sustainable watershed management in the face of climate change. It acknowledges the fact that local action planning increases institutional capacities and coordination and can be demonstrated using practical and participatory approaches and tools to building livelihoods and achieving ecosystems sustainability. Applied participatory tools for sustainable forest management are also inspired form those described by Evans et al. [25].

The process used in the current study aims at elaborating strategies (developed and applied with policy-makers) contributing to regional, subnational, and sectorial plans for sustainable resources management, poverty alleviation, and economic development, while considering socioecological priorities, institutional aspects, and the potential impacts of climate change. A set of tools are thus tailored to reach this target, including the following.

(i) Stakeholders analysis: analysis of the different stakeholders directly and indirectly involved in the management of the upper Akkar's natural resources, their roles and impact(s) on decision-making, and their mutual interactions.

(ii) Problem tree analysis: participatory identification of problems related to the sustainable management of forest resources in the watershed, their causes, root causes, and eventual impacts on the socioecological systems.

(iii) Field ecological surveys: field assessment of forests vulnerability and adaptive capacity in the face of climate change and anthropogenic pressures through forestry profiles assessments and analysis of forests vitality and inherent resilience. 
(iv) Social surveys: open-ended and close-ended questionnaires addressed to local and national stakeholders to thoroughly identify the impact(s) of each on the management and sustainability of forest resources.

(v) Objective tree development: computation of problems in the problem tree to objectives, where causes and root causes are converted into means and impacts are converted into ends.

(vi) Scenario building and strategizing: joint planning and strategizing with stakeholders to develop guidelines and action plans for sustainable resources management. Scenario building methodology is inspired from "Lebanon's second national communication to the United Nations Framework Convention for Climate Change" [4].

(vii) Pilot actions identification and prioritization in order to achieve forest sustainability in a complex socioeconomic and natural context (Figure 1).

Most of these tools were implemented through a participatory approach during workshops, working sessions, and one-to-one meetings, starting from the stakeholders' analysis to the prioritization process. Stakeholders were gathered on several occasions to discuss and exchange the key issues of concerns related to forest sustainability in north Lebanon, where every participant had the opportunity to communicate on his involvement in resources management, his long-term vision for the upper Akkar watershed, and the extent to which his contribution can effectively affect resources management.

Likewise, a collective workshop held with local and national authorities enabled the development of a participatory problem tree highlighting the main problem facing the region along with its causes, root causes, and impacts on a larger scale. This step paved the path towards numerous other gatherings where stakeholders computed the problems into operational objectives, built scenarios and strategies, and suggested priority actions for sustainable forest management. Close-ended and open-ended questionnaires (addressed on basis of one-to-one meetings with 38 key stakeholders, e.g., heads of municipalities, tribe members, local and international nongovernmental organizations working in the area, grazers, farmers, quarry owners, women, etc.) further served as a baseline to understanding local communities' basic interactions with natural resources and as tools to apprehend deeper details about these interfaces. These questionnaires addressed queries related to several fields such as grazing, logging, medicinal and aromatic plants harvesting, water use, patterns of forest frequentation and purposes, and governance, which underlined the interdependence degree between communities and forests. Both the ecological and social aspects were recorded for each field. Examples of closeended inquiries are for instance in the grazing section: what is the estimated number of grazers (herds) undergoing grazing activities in the forest? $(1-3,3-5$, and $>5)$; what is the main type of herds? (goats, sheep, other); what is the estimated number of animals per herd? $(<50,50-100$, and $>100)$; what are the main products sold by grazers? (dairy products, meat, small goats/sheep, and wool); what is the estimated income generated as a result of grazing activities per year? (<3000 USD, 3000-4000 USD, and >4000 USD); how many families are benefiting from it? $(<5,5-10$, and $>10)$. Openended questions included questions like the following. How is sewage treated in the village? Is the amount of water available satisfactory to match basic needs and meet services? What are the percentages of privately owned and publically owned forest lands?

This social approach was backed up with a scientificbased approach relying on concrete field assessments. An ecological vulnerability assessment of the upper Akkar forests in the face of climate change and anthropogenic pressures was performed in order to underline the degree to which forests are affected by global changes and human pressures, knowing that forest cover in the upper Akkar watershed is estimated at $78 \mathrm{Km}^{2}$ (about $69 \%$ of the overall watershed area-113 $\mathrm{Km}^{2}$ ). Ecological vulnerability assessments revolved around two main pillars including the analysis of current forests dynamics and potential evolution in light of ongoing and expected changes (forestry profiles, identification of threat indicators, assessment of forests inherent resilience, etc.) and forests vitality assessment based on entomological surveys (cedar buds monitoring, pheromone traps, etc.). During the field work, forest vulnerability assessments were undertaken in the area in four of its most representative stands (a high altitude mixed conifers forest of C. libani, A. cilicica, and J. excelsa, a relic stand of Q. cerris, and two mixed Q. calliprinos and $P$. brutia forests). Forest typology (combining ecological site attributes with stands characteristics) and forest vitality assessments were achieved in order to assess the state of the woodlands in the upper Akkar.

Social data (mainly that of the 38 gathered questionnaires) was qualitatively analyzed and extrapolated in order to achieve a better understanding of the socioeconomic system's impact on natural resources management. However, field data related to the ecological surveys was quantitatively analyzed [19]. Besides, information gathered through workshops, meetings, and working sessions was systematically kept integral, as it reflects the direct input of local and national stakeholders.

\section{Results}

In the results' display, municipalities, tribes, grazers, loggers, farmers, women, NGOs, cooperatives, schools, scouts, and local religious entities are referred to as the local stakeholders, whereas ministries, politicians, universities, and other national institutions are considered as national stakeholders.

Stakeholders' analysis was the first stage of the multistakeholder process. This step enabled the unanimous identification of the primary and secondary stakeholders involved in the management of the upper Akkar watershed's resources, their roles, prime movers, weaknesses, and mutual interactions. This was achieved through a collective meeting with all potential actors. Results exhibited that primary stakeholders were tribe members, small and large farmers, grazers, loggers, quarry owners, local political figures, watershed's municipalities, women, local and national NGOs working in the area, ministries (of environment, agriculture, interior 


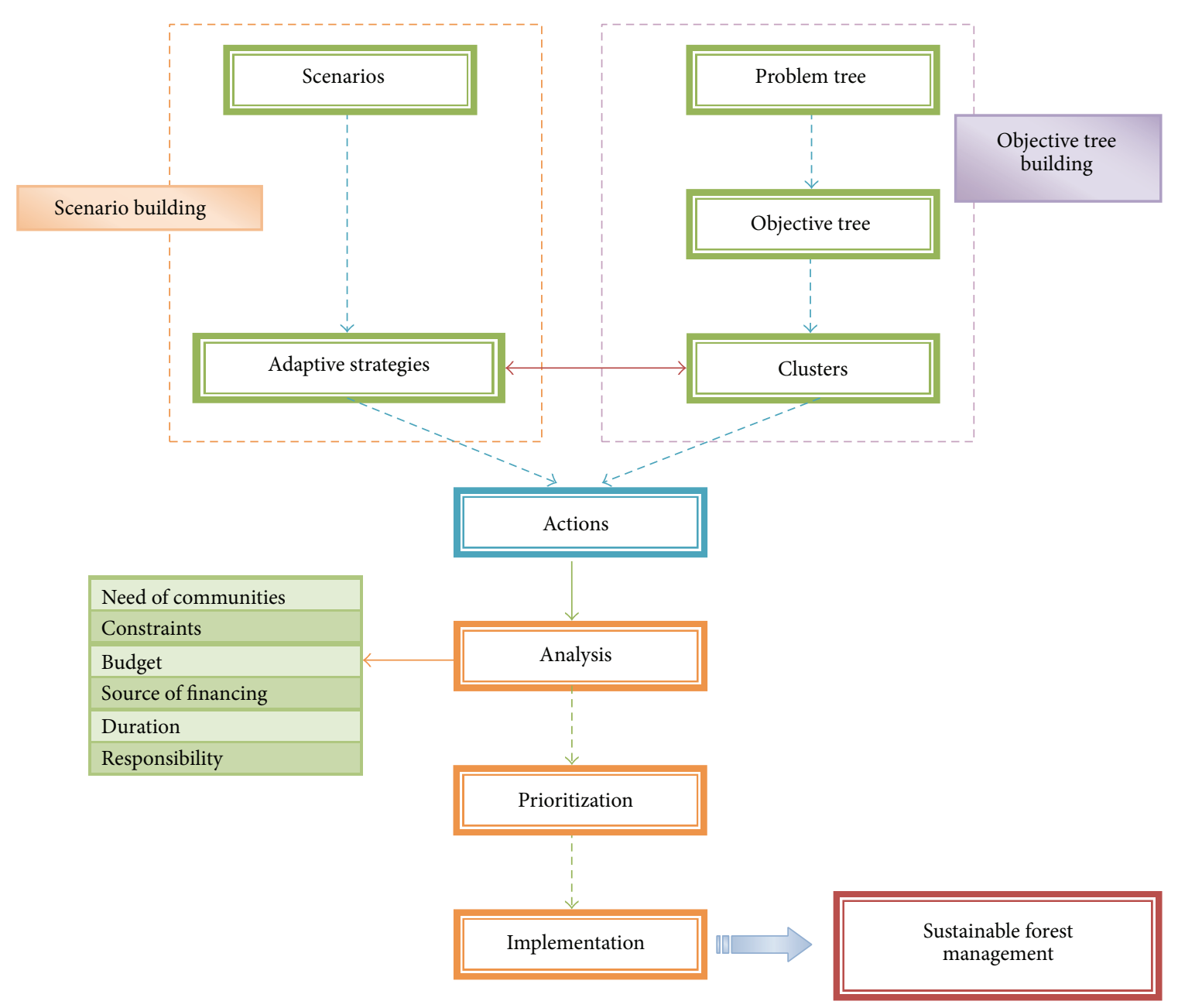

FIGURE 1: "Back-to-back" methodological approach for sustainable forest management.

and municipalities, public work and transport, energy and water, tourism, and defense), the council for development and reconstruction (CDR), and donors, whereas secondary stakeholders were identified as hunters, scouts, civil defense, universities, schools, religious institutions, and tour operators.

The roles and impacts of each stakeholder on both the socioeconomic and environmental levels were then thoroughly identified (Table 1). This assessment enabled a first documentation of the different stakeholders' contributions in resources management and/or exploitation along with the impact of their activities on the sustainability of these latter and the local economy. Differences in the roles and impacts varied from a stakeholders' category to another depending on whether concerned groups are direct users (exploiters), end-users, or decision-makers. In the last case, results showed a remarkable conflict of interests in decision-making processes between local and national stakeholders, where local tribes' authority on the ground somehow outweighed that of national institutions.

Interactions between the different actors were next assessed to evaluate potential coordination efforts. Few outcomes (given the relatively large number of stakeholders involved in this study, only few outcomes of the communication analysis exercise are displayed in Table 2; the matrix exhibits all the main possible combinations of potential results and includes major stakeholders) of this analysis are illustrated in Table 2, which exhibits the degree to which a relation between 2 given stakeholders is strong or weak, potentially important or not. Such an evaluation highlights the gaps in the stakeholders' communication network and consequently underlines the importance of acting to strengthen the collaboration between the different parties to achieve a sustainable system of stakeholders' cooperation.

An interesting observation is highlighted between municipalities and ministries: while both of them ought to be mutually cooperating to reflect a conceptual solid relation, the reality reveals a practical weakness in collaboration efforts. This result stresses the importance of improving partnerships between local and national stakeholders, while mostly activating the role of ministries in the management of the upper Akkar's natural resources.

Visioning was the next step of the participatory planning. Meetings and workshops conducted with local and national stakeholders resulted in the identification of a common vision for the upper Akkar region: "natural resources in the upper 
TABLE 1: Analysis of primary stakeholders' roles and impacts on the socioeconomic and environmental levels in the upper Akkar watershed.

\begin{tabular}{|c|c|c|}
\hline Stakeholder & Roles and impacts & Notes \\
\hline Members of tribe & $\begin{array}{l}\text { (i) Primary decision-makers in the Karmshbat village (highest peaks of the } \\
\text { upper Akkar watershed) and its surroundings } \\
\text { (ii) Major consumers of natural resources (mainly agriculture, quarrying, } \\
\text { logging, and grazing) }\end{array}$ & Local authority \\
\hline Small farmers & $\begin{array}{l}\text { (i) Owners of most of the agricultural lands } \\
\text { (ii) Play a major role in the local economy } \\
\text { (iii) Major consumers of water resources }\end{array}$ & $\begin{array}{l}\text { (i) Own high percentage of } \\
\text { seasonal agricultural crops } \\
\text { (ii) Some are grazers }\end{array}$ \\
\hline Large farmers & $\begin{array}{l}\text { (i) Owners of large agricultural tracts } \\
\text { (ii) Play a major role in the regional economy (import/export) } \\
\text { (iii) Major consumers of water resources }\end{array}$ & \\
\hline Grazers & $\begin{array}{l}\text { (i) Protect forests from foreigners } \\
\text { (ii) Play a minor role in the local economy (restricted to few families) } \\
\text { (iii) Depend on forest for grazing and water resources for cattle feeding } \\
\text { (iv) Affect natural forest dynamics }\end{array}$ & $\begin{array}{l}\text { (i) Poor community } \\
\text { (ii) Some are small farmers too }\end{array}$ \\
\hline Loggers & $\begin{array}{l}\text { (i) Depend on forests for wood extraction } \\
\text { (ii) Exploit wood for local use only (cooking, heating, etc.) } \\
\text { (iii) Contribute to forest degradation }\end{array}$ & \\
\hline Quarry owners & $\begin{array}{l}\text { (i) Depend on quarrying as a main income generating activity } \\
\text { (ii) Play a major role in the watershed economy } \\
\text { (iii) Deeply affect natural resources and landscapes (forests, soils, and water) } \\
\text { and contribute to ecosystems degradation }\end{array}$ & Are mainly members of the tribe \\
\hline Local political figures & $\begin{array}{l}\text { (i) Major role in lobbying for the region } \\
\text { (ii) Major role in decision-making }\end{array}$ & Rarely present in the region \\
\hline Municipalities & $\begin{array}{l}\text { (i) Local decision-makers and policy-makers } \\
\text { (ii) Influential role in forest and water resources management } \\
\text { (iii) Major role in water distribution to the villages }\end{array}$ & \\
\hline Women & $\begin{array}{l}\text { (i) Responsible for households } \\
\text { (ii) Major consumers of resources (water, plants harvesting, heating, etc.) } \\
\text { (iii) Form women cooperation (role in environmental awareness, empowering } \\
\text { women's livelihoods, etc.) } \\
\text { (iv) Minor role in local economy (handicraft and food provision production) }\end{array}$ & Some of them are farmers \\
\hline $\begin{array}{l}\text { Local and national } \\
\text { NGOs }\end{array}$ & $\begin{array}{l}\text { (i) Major role in fundraising } \\
\text { (ii) Implement environmental and developmental projects } \\
\text { (iii) Support environmental education and livelihoods } \\
\text { (iv) Promote sustainable management of natural resources }\end{array}$ & \\
\hline Ministries & $\begin{array}{l}\text { National authorities responsible for the implementation of legislations related } \\
\text { to infrastructure and resources management and for providing security to the } \\
\text { area }\end{array}$ & Weak representation in the area \\
\hline $\begin{array}{l}\text { Council for } \\
\text { development and } \\
\text { reconstruction }\end{array}$ & $\begin{array}{l}\text { (i) Major role in planning and land-use management } \\
\text { (ii) Implementation of megaprojects (dams, infrastructures, etc.) } \\
\text { (iii) Support for agricultural projects }\end{array}$ & \\
\hline Donors & Fund providers & \\
\hline
\end{tabular}

TABLE 2: Stakeholders' communication analysis.

\begin{tabular}{|c|c|c|c|c|c|c|}
\hline Stakeholder & Ministry of Environment & Women cooperative & Municipalities & Grazers & Farmers & Members of the tribe \\
\hline Members of the tribe & +1 & -1 & +1 & +2 & +2 & \\
\hline Farmers & +1 & -1 & +1 & -2 & & \\
\hline Grazers & +1 & -1 & +1 & & & \\
\hline Municipalities & +1 & +1 & & & & \\
\hline Women cooperative & -1 & & & & & \\
\hline Ministry of Environment & & & & & & \\
\hline
\end{tabular}

Communication analysis: 2: strong relation; 1: weak relation; +: important relation; -: not important relation. 
Akkar watershed are sustainably managed through an active multistakeholder participatory approach."

The visioning process was followed by a joint development of a problem tree (Figure 2) highlighting the main problem to which the watershed is exposed and that appeared to be related to not only the mismanagement of forest resources but also water resources. The causes and root causes behind this problem were consequently identified as well as the potential long-term impacts to which it can lead in case no action is undertaken. This user-friendly tool smoothed the flow of the participatory process. Together, stakeholders built a problem tree using papers and pencilsan easy approach to get people acquainted with complex aspects framing their livelihoods. Problem tree building was hence the result of an active participatory approach, where the root causes behind forests unsustainable current state were highlighted. The complexity of this tree clearly unveils the interdependence of livelihoods, politics, and forest management and confirms the link between ecosystems and livelihoods sustainability [24]. For instance, the lack of income generating activities combined with water shortage and absence of law enforcement drives local communities to shift from agriculture to overgrazing, hunting, and/or illicit logging, which jeopardizes forest resources in a marginalized area where inhabitants lack environmental awareness. Dealing with forest management in this region is thus strictly related to dealing with livelihoods, institutions, and politics as well.

The problem tree uncovered the interface between socioeconomic and ecological systems from a "stakeholders" point of view and pinned down the key institutional and legal roots leading to forests mismanagement in the upper Akkar. However, the good knowledge of prevailing ecological factors and forest stands specificities remains an important step when approaching the problems related to climate change [26]. Therefore, a more scientific assessment was performed in order to validate, confirm, and give pertinent weight to the issues raised by local and national actors and also to complement the social approach in order to further reflect the impacts of anthropogenic misdeeds along with the tangible effects of climate change on forests.

Results of the forest vulnerability assessments [19] revealed that forests are heavily impacted by engrained unsustainable anthropogenic practices which are radically challenging the survival of the species and the resilience of the stands. Forest fires and overgrazing are the key issues of concern in the area followed by abusive wood logging and uncontrolled urban sprawl. The plodding effects of climate change will mainly amplify the consequences as species like A. cilicica, Q. cerris, P. brutia, C. libani, J. excelsa, and J. foetidissima are at their southern limits of extension [27]. These findings had yet been previously mentioned by local communities. Nonetheless, the multidisciplinary approach was needed to refine and create a better understanding of the problems, while searching for solutions based on a new perception of complex situations.

Arising from the problem tree analysis and the results of the vulnerability assessment, an objective tree was elaborated through the conversion of each "problem" into an "objective," each "root cause" into a "mean," and each "effect" into an "end." The objective tree sets the main objectives to be achieved for improving natural resources management while exhibiting the means that must be attempted for that purpose and the ends that ought to be reached. As a result, the core problem is converted into a long-term objective assuming "water and forest resources are sustainably managed in the upper Akkar watershed." Means to achieve this objective include forest fires control, grazing management, and awareness raising (Figure 3 ).

The identified objectives were then clustered together into categories. Defined clusters shall orient strategy building while providing thematic bases to attempt. Subsequently, five clusters were identified.

(i) Sustainable technologies: using sustainable technological means to achieve proper management of natural resources.

(ii) Livelihoods upgrading: livelihoods boosting and poverty alleviation through the establishment of sustainable income generating activities for local communities along with women and local active stakeholders' empowerment.

(iii) Sociopolitical reform: conflict resolution amongst local and national stakeholders, law enforcement, and capacity building for an improved coordination between governmental entities.

(iv) Awareness: raising awareness among local stakeholders about sustainable environmental management priorities.

(v) Sustainable forest management: targeting full commitment to forest sustainability in all undertaken endeavors.

In conjunction, two scenarios (an optimistic and a pessimistic scenario) were built with local and national stakeholders in order to tackle possible combinations of threats and needs and approach sustainable forest management, environmental changes, participatory planning, sociopolitical situation, and availability of financial resources in the upper Akkar. To each scenario, adaptive strategies were conceived to answer all identified gaps and better orient management measures (Table 3).

These two scenarios are meant to meet one common goal which feeds back into the previously defined vision: "natural resources in the upper Akkar region are sustainably managed through an active multistakeholder participatory approach."

This common goal is defined as follows: "mitigate social and environmental changes and achieve forest sustainability through active participatory planning, increased awareness on environmental priorities, and adaptive management mainstreaming forest conservation and livelihoods upgrading."

The scenario building approach perfectly converged with the participatory objective tree building process, where identified clusters met with suggested strategies. Based on that, several actions dealing with the different aspects were jointly suggested and prioritized upon specific criteria including the needs of the local communities, constraints for 


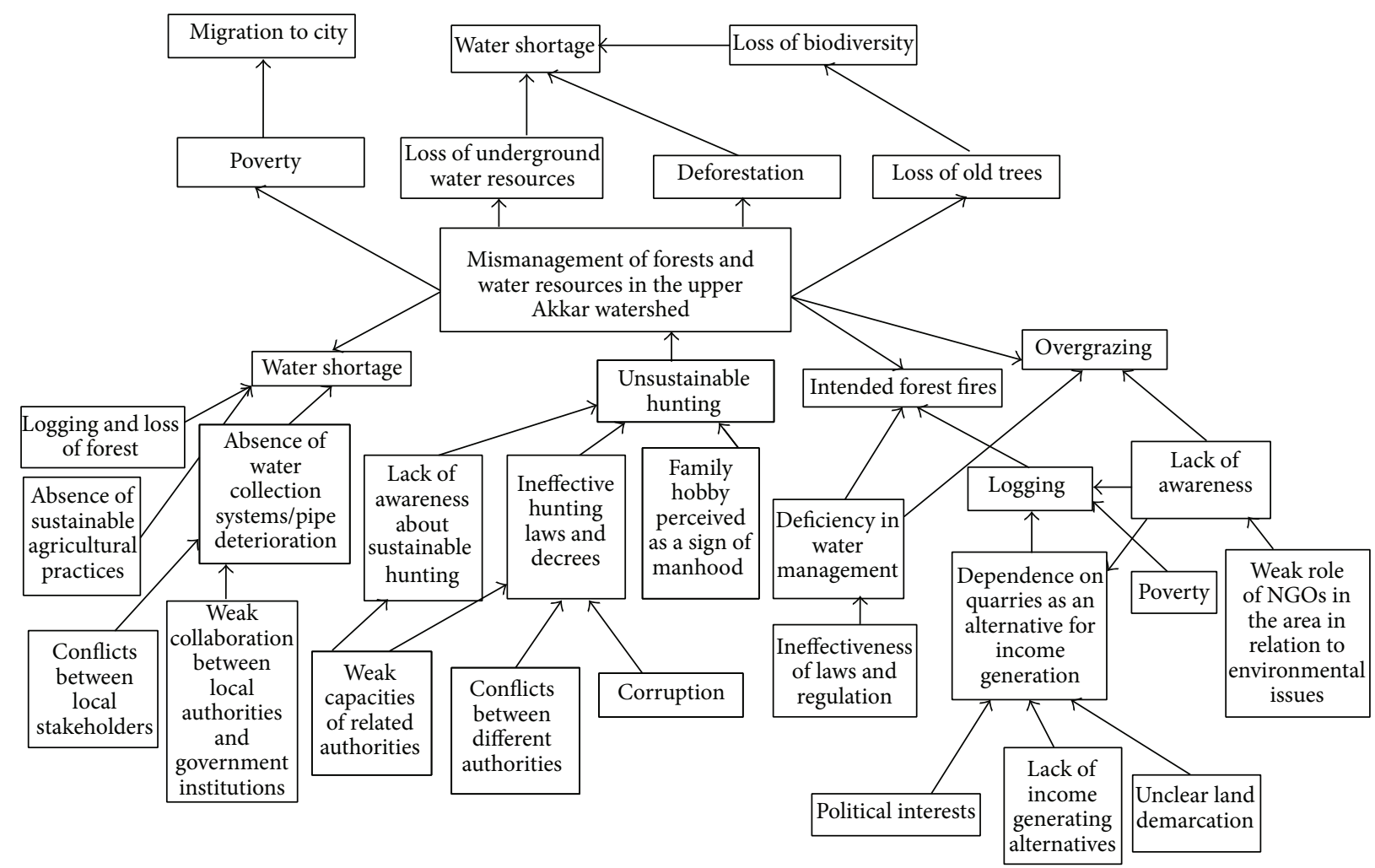

FiguRE 2: Problem tree for mismanagement of forests and water resources in the upper Akkar watershed.

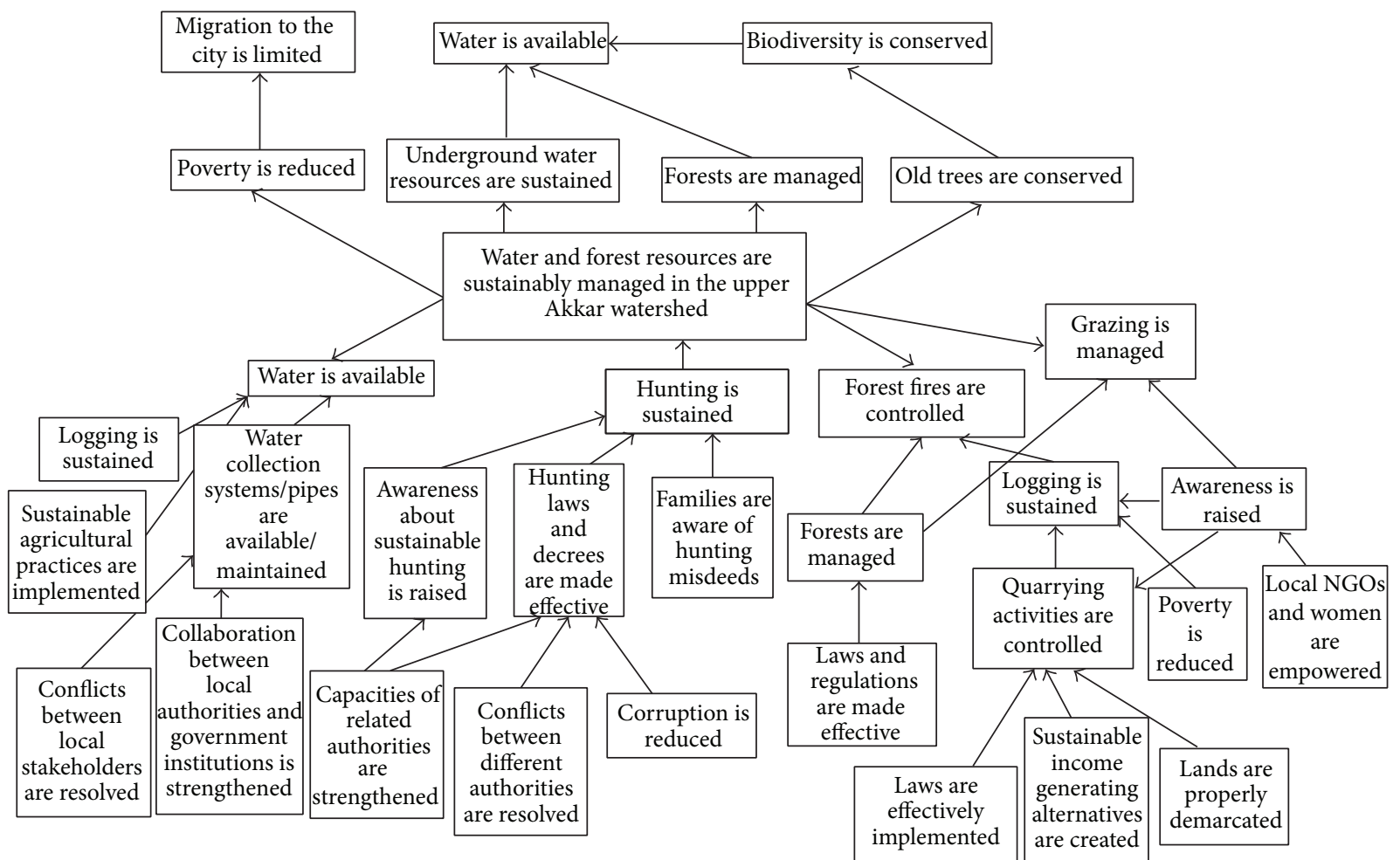

FIGURE 3: Objective tree for sustainable management of water and forests resources in the upper Akkar watershed. 
TABLE 3: Scenarios and strategies.

Scenario A: optimistic scenario

(i) Impacts of climate change are not perceived in the upper Akkar region neither on the social nor on the ecological level for the 20 coming years.

(ii) All stakeholders are actively involved in the management of the area's natural resources (mainly forests and water) through an active participatory planning.

(iii) Sociopolitical situation is stable.

(iv) Financial resources and funds are available for the implementation of sustainable management actions.
The plodding impacts of climate change will not be affecting the upper Akkar social and ecological systems for at least the 20 coming years.

Neither natural ecosystems nor social systems will be affected by eventual changes in climate trends and consequently livelihood assets and ecological features are safe from climatic disturbances that could distress water availability, impact the vitality of forests, and thus impede the ability of local communities to generate income.

Municipalities, federations, local communities represented by tribes, NGOs, cooperatives, natural resources exploiters (farmers, shepherds, hunters, loggers, etc.) and end-users, women, youth, and marginalized groups are actively involved in the management of the area's resources through an active participatory planning.

Stakeholders abide by common vision for the area and implement sustainable measures to boost their livelihoods and improve their living standards.

Sociopolitical situation in the area is stable. No social, tribal, religious, political, or transboundary tensions or conflicts exist.

Governance over natural resources management is prioritized and well organized amongst stakeholders.

Financial resources are available from municipal funds, private donations, and fundraising activities by donors ready to invest in the area and are invested in the implementation of sustainable actions aiming at the conservation of the area's social, agricultural, and ecological assets, mainly forest conservation.

\section{Strategy A}

(1) Maintaining the use of sustainable technologies

(2) Maintaining a sustainable management of natural resources

Aims at upholding/preserving/maintaining the use of sustainable technologies and at implementing adaptive measures for environmental management to mitigate the expected impacts of climate change in a scenario where local communities and all active stakeholders are.

(i) already aware of the importance of the sustainable management of natural resource;

(ii) in constant search for funds to implement adaptive management measures.

Scenario B: pessimistic scenario

(i) Climate change impacts are currently deeply altering social and ecological systems in the upper Akkar region.

(ii) No participatory planning amongst stakeholders exists, the latters not being actively involved in the management of the area's natural resources.

(iii) Sociopolitical situation is unstable.

(iv) Financial resources and funds are not available for the implementation of sustainable management actions.
Current impacts of climate change are deeply affecting social, agricultural, and ecological systems.

(i) Local communities' ability to cope and adapt to climate change impacts is low, their dependency on natural resources exploitation is pronounced, and no sustainable alternative income generating activities are provided. The social system is highly vulnerable to climate change effects.

(ii) Agricultural production is affected due to water shortage, and farmers are diverting from agriculture to other income generating activities such as livestock production (grazing), hunting, quarrying, and other unsustainable practices. Forest resources are progressively depleted and their sustainability is challenged. (iii) Ecosystems functionalities are altered (water infiltration, erosion control, etc.) and their resources are exhausted (trees death, loss of biodiversity, etc.) due to global changes and heavy anthropogenic pressures.

No participatory planning amongst stakeholders exists. Governance over natural resources management is nonsystematic and overlaps between several authorities/stakeholders engendering chaos in management priorities. No common long-term vision is identified for the area and local stakeholders do not adopt participatory planning approaches for the area's resources management. Moreover, no solid coordination with national authorities is settled and the area is left without national strategies for development along with unenforced laws.

Sociopolitical situation is unstable and conflicts amongst stakeholders mainly on natural resources governance are pronounced. Transboundary tensions and migration of foreigners to the area affect local livelihood conditions and further threaten the social balance and the area's natural resources. The execution and sustainability of any implemented action are therefore hindered.

A lack of financial resources to reduce the area's vulnerability to global changes through the implementation of sustainable actions exists. Neither municipality nor private funds are made available and fundraising activities are limited. 
TABLE 3: Continued.

Strategy B

(1) Upgrading livelihoods of local communities

(2) Raising awareness on sustainable exploitation and management of forests and other resources

(3) Engaging local actors in the management of the natural resources along with law enforcement (sociopolitical reform)
Aims at increasing the resilience of local communities in face of a changing, complex environment through

(i) providing them with sustainable alternative income generating activities aiming at improving their livelihoods and diverting them from unsustainable practices;

(ii) raising their awareness on environmental priorities and the importance of participatory planning for improved natural resources governance;

(iii) engaging them in decision-making processes related to natural resources management through the creation of local committees, CBOs (community based organizations), cooperatives, and so forth and empowering women, youth, and marginalized groups in such processes.

This strategy stresses providing local communities with tools and skills to combat the impacts of changes, for them to be able to track and avoid the depletion of their area's natural resources. implementation, budget, sources of financing, duration, and responsibility for implementation.

Participatory planning empowered local communities by involving them in decision-making processes and further engaged national authorities. It gave pertinence to suggested actions and motivated local implementation. The following actions reflect the efforts of a long joint planning.

(i) Rehabilitate old water tanks, maintain existing water networks, and install new water infrastructure for irrigation in the Aydamoun village (located at the highest peak of the watershed, where millennium mixed stands of conifers lie) in order to decrease water wastage and sustain agricultural practices. This will reduce pressure on forest resources generated by alternative overgrazing, logging, and excessive hunting activities due to water scarcity.

(ii) Empower local women grazers in Aydamoun while providing them with utensils for dairy production and provisioning and training them on sustainable sanitized production techniques and sustainable grazing practices. Such an initiative will improve their income and sustain grazing activities in the forests.

(iii) Promote alternative income generating activities to upgrade livelihoods in the area such as handcrafting, bee-hiving, production and commercialization of provision food, and establishment of ecotourism hubs (e.g., bed and breakfast). In this context, the promotion of ecotourism activities can have a crucial role in raising awareness of local communities and external visitors of the importance of conserving the natural and cultural features of the region, acquainting people with the forests and their patrimonial and ecological values, and boosting livelihoods through the creation of ecotourism centers, the appointment of local mountain guides, and so forth.

(iv) Develop and endorse a rotational grazing program for all four forests in the watershed in collaboration with grazers, municipalities, and other relevant stakeholders. (v) Develop and implement a forest management plan for pine and oak forests to control forest fires.

(vi) Establish a public garden in the region as a means to reduce pressure on the forests in the watershed caused by uncontrolled recreational activities.

(vii) Promote sustainable agricultural practices in the watershed (drip irrigation, rotation of cultures, use of organic pesticides, etc.) in order to reduce production costs and higher production yields and consequently enhance livelihoods.

(viii) Implement awareness campaigns in the whole region targeting all groups of stakeholders directly or indirectly involved in natural resources exploitation or conservation (youth, children, women, farmers, loggers, grazers, municipalities, etc.) in order to shape knowledge and engrain sustainability concepts that would later impact natural resources management demeanors.

(ix) Lobby with local political figures to develop a national strategic plan for the area recognizing the importance of natural resources conservation, mainly relic and exclusive forests.

(x) Develop a policy reform paper that supports local climate adaptation and resilience processes in order to catalyze and strengthen institutional interventions in a complex socioeconomic and natural context.

\section{Discussion}

So, is forest sustainability all about forests?

As discussed and confirmed by numerous socialists and naturalists, forest management is related not only to forests per se but also to the whole surrounding socioeconomic system in which these forests fall and which directly influences their sustainability [28-30]. Presented results validate this fact, as achieving sustainable forest management in the upper Akkar requires not only strict silviculture interventions but also a definite consideration of community needs and local economy. Dealing with forest management is thus delicately 
linked to dealing with water and agriculture management, livelihoods, economy, politics, laws, and food security. In that respect, forest resources management nearly always requires a multidisciplinary approach since most problems have many dimensions and cannot be appropriately handled through a monodisciplinary approach [31]. Multidisciplinarity is a key for the design of suitable options for forest management [32]. The integration of ecological assessments and participatory approaches and tools in this study highlights the interdependence of forests and communities and underlines the importance of considering water and land resources issues while picturing forest sustainability. As also confirmed by Pant et al. [33], appropriate forest management requires an integrated management of all resources. The lack of coordination at the policy level can however create confusions and problems with integrated management at the local level. Several studies also highlight the increasing recognition of local communities' empowerment (in terms of decisionmaking and good governance) as an important outcome of a participatory multidisciplinary multistakeholder approach $[7,34]$ which indeed was demonstrated throughout this study.

However, despite its effectiveness in mounting sustainable forest plans, the adopted multistakeholder approach reveals a major drawback which is time. Participatory planning is a time-consuming process which can easily drown financial and temporal resources. The current study is the result of three years of effort and is still in its early phases.

Besides, involving stakeholders can sometimes raise expectations that cannot be met, which can create distrust and hamper motivation. The goal is getting quality input without raising unrealistic expectations [35].

Consequently, the replicability of such a process is necessarily complex on a larger scale but can yet be very successful as long as it is applied on a watershed level.

Establishing participatory forest management involves a considerable amount of work, since introducing a new approach to forest management in a country or region is not an easy task. However, with gradual progress and a commitment to learning, foresters and communities alike can adopt sustainable practices for forest management leading to positive changes in the seemingly unstoppable wave of forest degradation [36].

Management of ecosystems is often jeopardized by political decisions initially aimed at promoting conservation and enhancing local actions with lasting impacts on the ecosystems. Therefore, as discussed by Khater et al. [37], approaching ecological problems is extremely complex and depends on effective social interactions. It is thus important to go beyond the frontiers of ecological sciences to achieve sustainable forest management. Still, the good knowledge of prevailing ecological factors and forest stands specificities remains an important step to approach the problems of climate change impacts and achieve optimal forest sustainability [2, 26]. An appropriate forest typology, combining ecological site attributes with stands characteristics, is thus a pertinent tool for silviculture and forest management. Some research results are beginning to further investigate forest dynamics and biological data in north Lebanon [20,
38-40] and consequently recommend specific management perspectives $[2,17,41-43]$.

\section{Conclusion and Challenges}

The adoption of a multitool, multidisciplinary, multistakeholder approach combines all possible aspects of a challenging context and unfolds complementary processes which feed back into one common goal. It enables the dissection of the problem into bits and pieces, which further enlighten concerns, weaknesses, and root causes, while envisioning future scenarios and building foundations based on pertinent scientific data. However, the success of such an approach can only be appraised after monitoring and evaluating postimplementation impacts.

This holistic multidisciplinary approach is quite an important departure from the monodisciplinary approach. Still, the sole development of more sustainable approaches is seldom. Such development must be complimented by longterm sustainability assessments, policy development, and capacity building in the local community and governing bodies. Only then will these developments effectively drive the change towards sustainable forest management. This should be not only done in north Lebanon but also widened to the best possible extent to the entire country and the Mediterranean region as a whole. The direct inclusion of nongovernmental organizations in multistakeholder research programs is of paramount importance in that regard. This would further enhance the research applicability in a context where there are growing expectations that academia will have a vital role to play in producing independent research that feeds into the decision-making processes.

The process of actively engaging communities and institutions in managing forest resources is certainly a commendable act, but will they manage to maintain this mutuality and always perform jointly in an extremely changing environment, where forests remain a bargaining chip against economy and politics in north Lebanon?

\section{Conflict of Interests}

The authors declare no conflict of interests.

\section{Acknowledgments}

This paper is a CNRS-L contribution as part of the Grant Research Program project "Towards a Sustainable Management of Forests in North Lebanon in the Face of Global Changes." It has been produced based on the results of the EU SEARCH project (Social, Ecological and Agricultural Resilience of Mediterranean Watersheds in the Face of Climate Change and Other Drivers of Change), implemented by the IUCN-Regional Office of West Asia (ROWA) in five countries: Lebanon, Palestine, Jordan, Egypt, and Morocco. In that regard, the authors wish to thank the IUCN for their constant support in achieving the results of this paper. This is a LIA O-LiFE contribution no. SA1-2014. 


\section{References}

[1] Secretariat of the Convention on Biological Diversity, Sustainable Forest Management, Biodiversity and Livelihoods: A Good Practice Guide, Montreal, Canada, 2009.

[2] P. Regato and R. Salman, Mediterranean Mountains in a Changing World: Guidelines for Developing Action Plans, IUCN Centre for Mediterranean Cooperation, Malaga, Spain, 2008.

[3] P. Quezel, "Biodiversité végétale des forêts méditerranéennes, son évolution éventuelle d'ici à trente ans," Forêt Méditerranéenne, vol. 2, no. 1, pp. 3-8, 1999.

[4] MoE/GEF/UNDP, Lebanon's Second National Communication to the UNFCCC, Ministry of Environment, Beirut, Lebanon, 2011.

[5] IPCC, "Climate change 2001: synthesis report. a contribution of working groups I, II, and III to the third assessment report of the intergovernmental panel on climate change," Tech. Rep., Cambridge University Press, Cambridge, UK, 2001.

[6] S. H. Schneider, "What is "dangerous" climate change?" Nature, vol. 411, no. 6833, pp. 17-19, 2001.

[7] G. Amente and T. Tadesse, "The contribution of participatory forest management towards good governance: the case of WAJIB approach in Ethiopia," in Proceedings of the 5th Annual Conference of the Ethiopian Foresters Association on "New Forest Management: The Contribution of Forests to the National Economy", Addis Ababa, Ethiopia, October 2004.

[8] M. Legay and J. Ladier, "La gestion forestière face aux changements climatiques: premières orientations d'adaptation en forêt publique. Le cas des forêts méditerranéennes," Forêt Méditerranéenne, vol. 29, no. 2, pp. 221-234, 2008.

[9] B. O. Springate, O. P. Dev, N. Yadav, and J. Soussan, "Community forest management in the middle hills of Nepal: the changing context," Forest \& Livelihoods, vol. 3, no. 1, pp. 5-20, 2003.

[10] (UN) United Nations, "Resolution adopted by the General Assembly 62/98: Non-legally binding instruments on all types of forests 2008".

[11] B. R. Sturtevant, A. Fall, D. D. Kneeshaw et al., "A toolkit modeling approach for sustainable forest management planning: achieving balance between science and local needs," Ecology and Society, vol. 12, no. 2, article 7, 2007.

[12] K. Evans, W. de Jong, and P. Cronkleton, "Future scenarios as a tool for collaboration in forest communities," Sapiens, vol. 1, no. 2, 2009.

[13] E. L. Tompkins and N. W. Adger, "Building resilience to climate change through adaptive management of natural resources," Tech. Rep., Tyndall Centre Working Paper, 2003.

[14] C. Khater, R. El-Hajj, T. Darwish, and M. Hamzé, "Forests in Lebanon: a cornerstone for conservation of a relic ecological heritage," The CIHEAM Watch Letter, vol. 25, pp. 24-27, 2013.

[15] E. J. Sattout and M. Abboud, National Self Capacity Assessment for Global Management. Thematic Biodiversity Profile, National Self-Assessment for Global Management, GEF/UNDP/MOE, Beirut, Lebanon, 2007.

[16] C. Khater and R. El-Hajj, "Terrestrial biodiversity in Lebanon," in Review and Perspectives of Environmental Studies in Lebanon, H. Kouyoumjian and M. Hamzé, Eds., pp. 141-169, INCAMEU/CNRS, 2012.

[17] R. El-Hajj and C. Khater, Environmental Mapping and Preliminary Ecological Vulnerability Assessment of the Upper Akkar Watershed, Lebanon, Search Partnership for Social, Ecological and Agricultural Resilience in the Face of Climate Change (Mada/SPNL/IUCN/EU), Beirut, Lebanon, 2011.
[18] F. Denno, C. Khater, and I. Peillen, Towards a National Park in Upper Akkar: Achievements, Challenges and Perspectives for 2005-2008, Mada, Beirut, Lebanon, 2009.

[19] R. El-Hajj, C. Khater, P. Varese, and N. Nemer, "Mediterranean ecosystems challenged by global changes and anthropogenic pressures:vulnerability and adaptive capacity of forests in North Lebanon," La Terre et la Vie. In press.

[20] E. J. Sattout and N. Nemer, "Managing climate change effects on relic forest ecosystems: a program for Lebanese cedar," Biodiversity, vol. 9, no. 3-4, pp. 122-130, 2008.

[21] W. N. Adger, P. M. Kelly, and N. H. Ninh, Eds., Living with Environmental Change: Social Vulnerability, Adaptation and Resilience in Vietnam, Routledge, London, UK, 2001.

[22] T. Downing, "Toward a vulnerability/adaptation science: lessons from famine early warning and food security," in Developing Countries and Sustainable Adaptation to Climate Change, J. Smith, R. Klein, and S. Huq, Eds., Imperial College Press, London, UK, 2003.

[23] J. C. Ribot, A. R. Magalhaes, and S. S. Panagides, Eds., Climate Variability, Climate Change and Social Vulnerability in the SemiArid Tropics, Cambridge University Press, Cambridge, UK, 1996.

[24] C. S. Sneddon, “Sustainability' in ecological economics, ecology and livelihoods: a review," Progress in Human Geography, vol. 24, no. 4, pp. 521-549, 2000.

[25] K. Evans, W. de Jong, P. Cronkleton et al., Guide to Participatory Tools for Forest Communities, Center for International Forestry Research (CIFOR), Bogor, Indonesia, 2006.

[26] M. Lindner, M. Maroschek, S. Netherer et al., "Climate change impacts, adaptive capacity, and vulnerability of European forest ecosystems," Forest Ecology and Management, vol. 259, no. 4, pp. 698-709, 2010.

[27] B. Abi-Saleh and S. Safi, "Carte de la Végétation du Liban au 1/500000 + Notice explicative," Ecologia Mediterranea, vol. 14, no. 1-2, pp. 123-142, 1988.

[28] H. Mogaka, G. Simons, L. Turpie, L. Emerton, and F. Karanja, Economic Aspects of Community Involvement in Sustainable Forest Management in Eastern and Southern Africa, IUCNThe World Conservation Union, Eastern Africa Regional Office, Nairobi, Kenya, 2001.

[29] I. P. Soloviy and W. S. Keeton, Ecological Economics and Sustainable Forest Management: Developing a Transdisciplinary Approach for the Carpathian Mountains, Lviv, Ukrainian National Forestry University Press, Liga-Pres, Kiev, Ukraine, 2009.

[30] T. J. Straka, "Evolution of sustainability in American forest resource management planning in the context of the American forest management textbook," Sustainability, vol. 1, no. 4, pp. 838-854, 2009.

[31] B. Foahom, The Scientific Approach to Sustainable Forest Management, with Particular Attention to Land-Use Planning and Social Aspects, Tropenbos International, Kribi, Cameroons, 1998.

[32] W. K. Sombroek, The Need for Common Methodologies in Consultation on a United Approach for Research in the Humid Tropical Forests, Tropenbos, Utrecht, The Netherlands, 1986.

[33] D. Pant, S. Thapa, A. Singh, M. Bhattarai, and D. Molden, "Integrated management of water, forest and land resources in Nepal: opportunities for improved livelihood," CA Discussion Paper 2, International Water Management Institute, Colombo, Sri Lanka, 2005. 
[34] L. A. Wily, "Forest governance lessons from Eastern and Southern Africa," in Proceedings of the AFLEG Ministerial Conference, Yaounde, Cameroon, October 2003.

[35] T. F. Yosie and T. D. Herbst, Using Stakeholder Processes in Environmental Decision Making. An Evaluation of Lessons Learned, Key Issues, and Future Challenges, The American Industrial Health Council, The American Petroleum Institute, and The Chemical Manufacturers Association, Washington, DC, USA, 1998.

[36] FARM-Africa/SOS Sahel Ethiopia, The Key Steps in Establishing Participatory Forest Management. A Field Manual to Guide Practitioners in Ethiopia, Best Practices Series No.1, Oromiya Bureau of Agriculture and Rural Development, Southern Nations and Nationalities Peoples' Region Bureau of Agriculture and Rural Development, Addis Ababa, Ethiopia, 2007.

[37] C. Khater, V. Raevel, J. Sallantin, J. D. Thompson, M. Hamzé, and A. Martin, "Restoring ecosystems around the Mediterranean basin: beyond the frontiers of ecological science," Restoration Ecology, vol. 20, no. 1, pp. 1-6, 2012.

[38] L. Awad, Ecogenetic diversity and survivorship of Abies cilicica populations in Lebanon [M.S. thesis], Université Saint-Esprit de Kaslik, Juniyah, Lebanon, 2009.

[39] I. Jomaa, Y. Auda, and C. Khater, "Contribution to the characterization of forest fragmentation on the eastern flank of Mount Lebanon over 33 years," Lebanese Science Journal, vol. 8, no. 2, pp. 59-74, 2007.

[40] E. Sattout, "Assessment of flora biodiversity and forest composition and structure in Akkar-Donnieh area, Setting the path towards the establishment of a national natural park in the region of Akkar-Donnieh project," Final Report, Mada/RSCN/SDC, Beirut, Lebanon, 2006.

[41] R. Koepsell, M. Bassil, and J.-E. Voss, Elaboration of Management Plans of Two Pine Forests in View of Sustainable Forest Management and Forest Fire Protection. ADELNORD Project, GFA Consulting Group, 2012.

[42] M. Saadieh, "The problems of forestry management in the Dannieh municipal union (North Lebanon)," Forêt Méditerranéenne, no. 32, pp. 439-454, 2011.

[43] J. Stephan, R. El-Hajj, N. Zakhia, G. Moukheiber, and C. Khater, "The North horizon forest trail, a new perspective for conservation and management of Dannieh forests, North Horizon forest trail project, GIZ/EFL-Federation of Municipalities of Dannieh," Initial Field Analytical Report, MADA, Beirut, Lebanon, 2011. 

